\author{
Cadernos de \\ ESTUDOS LINGUIISTICOS - (58.2), Campinas, pp. 345-367 - mai./ago. 2016
}

\title{
ADJUNTOS TEMPORAIS E MEASURE PHRASES: UMA PROPOSTA SEMÂNTICA ${ }^{1}$
}

\author{
RENATO BASSO ${ }^{2}$ \\ JOÃO FRANCISCO BERGAMINI-PEREZ ${ }^{3}$
}

\begin{abstract}
RESUMO: O estudo semântico dos fenômenos tempo-aspectuais é uma área importante da chamada "semântica de eventos". Um dos objetivos das pesquisas que investigam esse fenômeno é a delimitação dos diferentes tipos de eventos, denotados por predicados verbais (a acionalidade dos eventos), assim como a análise de nuances aspectuais e da referência temporal.

Os adjuntos temporais, como 'por X tempo'e 'em X tempo', são duas importantes ferramentas utilizadas para efetuarmos distinções acionais e aspectuais, desde os trabalhos de Vendler (1957). Contudo, há diversos adjuntos temporais para além desses dois, como 'durante $\mathrm{X}$ tempo', 'até $\mathrm{X}$ tempo' e 'de X a Y tempo’, cuja investigação semântica ainda é bastante incipiente.

Sendo assim, o objetivo principal deste artigo é apresentar uma análise semântico-pragmática dos últimos adjuntos mencionados acima, comparando-os com os adjuntos 'por X tempo' e 'em X tempo', com o intuito de fornecer a eles uma descrição nos termos da semântica formal das línguas naturais. Para tanto, investigaremos, por exemplo, os padrões de inferência que esses adjuntos engendram, as possibilidades de alcance do telos para certas combinações, interpretações habituais de eventos, dentre outras. Assim, tentaremos elucidar o papel de determinados adjuntos temporais em diferentes relações com predicados verbais.
\end{abstract}

Palavras-Chave: Adjuntos temporais, acionalidade, eventos, semântica, pragmática

ABSTRACT: The semantic study of temporal-aspectual phenomena is an important topic of "event semantics." One of the main goals of these studies is to delineate the different types of events, denoted by verbal predicates (the actionality of events), as well as the analysis of aspectual nuances and temporal reference.

Temporal adjuncts, such as 'por $\mathrm{X}$ tempo' ('for $\mathrm{x}$ time') and 'em $\mathrm{X}$ tempo' ('in $\mathrm{X}$ time'), are two important tools used to make actional and aspectual distinctions, and are used in the literature since Vendler (1957). However, there are several temporal adjuncts in addition to these two, such as 'durante $\mathrm{X}$ tempo' ('during $\mathrm{X}$ time'), 'até $\mathrm{X}$ tempo' ('until $\mathrm{X}$ time') and 'de $\mathrm{X}$ a Y tempo' ('from X to Y time'), which were not yet been investigated from a semantic point of view.

Thus, the main purpose of this paper is to present a semantic-pragmatic analysis of the aforementioned adjuncts, comparing them with 'por $\mathrm{X}$ tempo' ('for $\mathrm{X}$ time') and 'em $\mathrm{X}$ tempo' ('in $\mathrm{X}$ time'), in order to provide a description within the framework of natural language formal semantics. We investigate the inference patterns that such adjuncts engender, if the combination of perfective telic events with these adjuncts guarantees the interpretation that the telos of these event are reached, habitual interpretations, among others. We will try to elucidate the role of certain temporal adjuncts in different relations with verbal predicates.

Keywords: temporal adjuncts, actionality, events, semantics, pragmatics

\footnotetext{
${ }^{1}$ Agradecemos à FAPESP pelo financiamento que possibilitou a pesquisa por trás deste artigo.

${ }^{2}$ rmbasso@gmail.com

${ }_{3}^{3}$ jfbergaminiperez@gmail.com
} 

INTRODUÇÃO

A semântica de eventos, desde os trabalhos seminais de Vendler (1967), Davidson (1967), Parsons (1990), e vários outros, sempre se valeu de adjuntos temporais ${ }^{4}$ para estabelecer distinções entre eventos, principalmente aquelas que têm a ver não com aspecto verbal, mas sim com a natureza dos eventos. Essas distinções são, atualmente, conhecidas como "distinções acionais" (cf. Bertinetto, 1986), e correspondem a identificação de eventos télicos versus atélicos, durativos versus não-durativos, etc.

Apesar de haver diversos tipos de adjuntos temporais, sem dúvida os mais estudados foram os adjuntos 'em X tempo' e 'por X tempo', formados por uma preposição e uma measure phrase (MP). Neste artigo, ampliaremos o rol de adjuntos investigados, considerando também os seguintes: 'durante $\mathrm{X}$ tempo', 'de X a Y tempo' e 'até X tempo'. Analisaremos esses adjuntos em comparação com 'em X tempo' e 'por X tempo' devido ao fato de esses adjuntos já serem razoavelmente investigados e servirem, assim, como contraste para os adjuntos que ainda não foram alvos de investigações. Além disso, mais do que simplesmente analisar casos prototípicos dos usos desses adjuntos (como 'em X tempo' se combinar com eventos télicos perfectivos, e 'por X tempo' com atélicos), seguiremos a metodologia apresentado em AUTOR (2011), que considera todas as combinações possíveis entre aspecto, classes vendlerianas e os adjuntos em questão. Essa estratégia permitirá a análise de um grande número de casos e do acesso a uma teoria mais geral sobre os adjuntos temporais, que desenvolveremos ao longo deste artigo.

Finalmente, argumentaremos também, a partir das evidências que traremos, que é importante distinguir as MPs dos adjuntos em três tipos: MPs primárias, MPs secundárias e MPs atemporais. Tal distinção explicará as possibilidades de uso e combinação, bem como as interpretações dos adjuntos temporais que investigamos aqui.

Para atingirmos nossos objetivos, organizamos o presente artigo da seguinte forma: na seção 1, apresentaremos os principais conceitos da semântica de eventos que utilizaremos; na seção 2, apresentamos uma análise mínima dos adjuntos 'em $\mathrm{X}$ tempo' e 'por X tempo', que será nosso ponto de partida para; na seção 3, apresentarmos uma análise para os outros, começando por 'durante $\mathrm{X}$ tempo', depois 'de X a Y tempo' e então 'até X tempo'. Finalmente, na Conclusão faremos um balanço das ideias e dos resultados alcançados.

${ }^{4}$ Ao longo deste texto, faremos a simplificação, às vezes, de falar de modificadores de eventos ao invés de modificadores de predicados que denotam/se referem a eventos, por exemplo. Notamos, contudo, que se trata de uma simplificação, que apenas torna a leitura mais fluída. 


\section{CONCEITOS FUNDAMENTAIS}

Na semântica de eventos, os eventos são divididos em classes, chamadas muitas vezes de 'classes vendlerianas', que respondem pelo tipo ou natureza dos eventos - trata-se de sua acionalidade ${ }^{5}$ e determinar qual é a classe acional de um dado evento (i.e., sua acionalidade) é algo, em geral, feito por meio dos adjuntos temporais como os que investigaremos aqui. Porém, além das propriedades acionais relativas a eventos denotados/referidos por predicados verbais, devemos considerar o aspecto verbal no qual eventos são veiculados, bem como as diferentes referências temporais possíveis.

No que tange à noção de aspecto, adotaremos as noções encontradas no trabalho de Rothstein (2004), que, ainda que não sejam livres de controvérsias, são adotadas por vários pesquisadores e dão conta de diversos fatos de língua. Sendo assim, consideramos aspecto verbal como o modo pelo qual um dado evento é apresentado ou veiculado. Há dois desses modos principais: i. o aspecto perfectivo, no qual um evento é representado como não mais em andamento, ou seja, não é mais o caso; ii. o aspecto imperfectivo, no qual nada é dito em relação ao evento ter cessado. Para melhor ilustrar essa definição, tomamos um exemplo apresentado em AUTOR (2011) e Pires de Oliveira \& AUTOR (2010):

(1) João leu o livro.

Nesses trabalhos, a proposta para o aspecto perfectivo é que, em (1), por exemplo, não há a indicação de que João leu o livro até o fim necessariamente ${ }^{6}$, mas que ele não está mais lendo o livro, ou seja, que o evento veiculado cessou ou não ocorre mais. $\mathrm{O}$ aspecto perfectivo simplesmente indica que um dado evento não é mais o caso para um tempo de referência relevante.

Por sua vez, o aspecto imperfectivo pode ser ilustrado por uma sentença como a em:

(2) João estava lendo o livro.

A proposta para o aspecto imperfectivo é de que o evento veiculado ainda é o caso para um momento de tempo relevante, ou seja, mesmo que não seja especificado o momento no qual este evento continua, existe a indicação de que seu fim ainda não foi alcançado. $\mathrm{O}$ aspecto imperfectivo não indica que um dado evento não é mais o caso.

${ }^{5}$ Quando falamos em classificação acional ou classes acionais, adotamos como base a classificação feita por Vendler (1957), que discutiremos com mais detalhes nas próximas páginas do trabalho.

${ }^{6}$ Pires de Oliveira e Basso (2010) oferecem uma série de argumentos a favor de uma interpretação chamada "fraca" do perfectivo neste caso, ou seja, não se comprometem com o acarretamento de que o livro está (completamente) lido. Por ora, deixaremos de lado as motivações dos autores para tanto. 
Com relação à acionalidade, consideramos como fonte principal para as distinções que utilizaremos o trabalho de Vendler (1957), no qual é proposta uma classificação acional (i.e., que tem a ver com o tipo ou a natureza dos diferentes eventos que podem ser denotados/referidos por predicados verbais em língua natural). Essa distinção tem quatro classes, chamadas de classes acionais ou classes vendlerianas, e que são: atividades, estativos, accomplishments e achievements. Sua categorização é feita através de traços descritivos para cada tipo evento, como duratividade, estatividade (ou dinamicidade) e telicidade, uma vez que cada tipo de evento é resultado da presença (ou não) de cada um desses traços. Além disso, podemos encontrar contrapartes linguísticas relacionadas a esses traços considerando a compatibilidade ou não de, por exemplo, adjuntos temporais específicos com eventos de uma determinada classe acional, que revelariam a presença de características como [+ duratividade].

De maneira simplificada, a classificação vendleriana pode ser considerada de acordo com o quadro abaixo:

Tabela 1. Classificação vendleriana dos eventos

\begin{tabular}{|c|c|c|c|}
\hline & [durativo] & [télico] & [dinâmico] \\
\hline accomplishments (acc.) & + & + & + \\
\hline achievements (ach.) & - & + & + \\
\hline estativos (est.) & + & - & - \\
\hline atividades (ativ.) & + & - & + \\
\hline
\end{tabular}

$\mathrm{O}$ traço de duratividade se refere à possibilidade de o evento se desenvolver ou se desenrolar no tempo; portanto, eventos durativos se desenvolvem no tempo e eventos não-durativos ocorrem de maneira instantânea ${ }^{7}$. Por exemplo:

(3) João desenhou por 20 minutos. (at. / traço + durativo)

(4) João desenhou uma casa por 30 minutos. (acc. / traço + durativo)

(5) João teve fome por 15 minutos. (est. / traço + durativo)

Por sua vez, a telicidade é marcada quando existe um ponto final intrínseco ligado ao evento veiculado por dado predicado; esse ponto indica o final do evento télico, e a partir dele o evento não pode mais progredir, servindo também para definir o próprio evento. Podemos exemplificar esse traço com as sentenças abaixo 'note que ser télico ou atélico não tem relação com o aspecto verbal':

${ }^{7}$ Uma maneira de visualizar a duratividade é a compatibilidade dos predicados que veiculam tais eventos com adjuntos do tipo 'por X tempo': somente eventos durativos são compatíveis com esse adjunto numa leitura de duração de evento; eventos não-durativos quando combinados com esse adjunto ou resultam em sentenças estranhas, ou temos interpretação de repetição de evento.

${ }^{8}$ Conforme defendido por Basso e Pires de Oliveira (2010) e Bertinetto (2000), o alcance do telos de eventos télicos está ligado ao aspecto perfectivo (somente eventos télicos que não são mais o caso podem não sê-lo devido ao alcance de seu telos). Contudo, ser ou não télico não é algo ligado ao aspecto verbal. 
(6) João desenhou uma casa. (evento télico perfectivo)

(7) João estava desenhando uma casa. (evento télico imperfectivo)

(8) João correu. (evento atélico perfectivo)

(9) João estava correndo. (evento atélico imperfectivo)

O ponto final relevante aqui é conhecido como telos (do grego "meta", “objetivo"), e os eventos télicos são os achievements (que são também não-durativos) e os accomplishments (que são também durativos). Por exemplo:

(10) Maria desenhou um círculo. (acc.)

(11) Clara chegou. (ach.)

Outra característica importante dos predicados que veiculam eventos télicos é o fato de serem sempre compatíveis com o adjunto 'em X tempo'. Além disso, adjuntos do tipo 'em X tempo', quando combinados com predicados que veiculam um evento do tipo achievement, denotam a medida de tempo do que podemos chamar de "fase preparatória" dos achievements, ou seja, um tempo anterior ao alcance do seu telos; diferentemente dos accomplishments, para os quais a medida de tempo do adjunto 'em X tempo' simplesmente mede o desenrolar do próprio evento até o seu telos, devido ao seu caráter durativo.

Finalmente, o traço de dinamicidade se refere ao caráter agentivo ou não do sujeito da sentença no evento em questão, por exemplo, eventos do tipo estativos não envolvem um agente, mas um experienciador ${ }^{9}$.

Podemos ver o papel importante dos adjuntos temporais na delimitação das classes vendlerianas. Porém, essa não é a única função desses adjuntos, pois eles também podem alterar a interpretação dos predicados verbais com os quais são combinados. A seguir, apresentamos, resumidamente, algumas considerações sobre os adjuntos 'em X tempo' e 'por X tempo' com base em AUTOR (2011), para depois aplicar as mesmas ideias aos adjuntos 'durante $\mathrm{X}$ tempo', 'de X a Y tempo' e 'até X tempo'10.

\footnotetext{
${ }^{9}$ Para caracterizar a presença ou não deste traço em um evento, podemos colocar a construção "fazer o mesmo" para cada um dos predicados que veiculam um evento. Para um evento estitavo, que tem experienciador e não sujeito agente, esperamos que a sentença resultante seja ruim como em ?? "Carlos sabe Inglês, e João faz o mesmo.”.

${ }^{10}$ A tabela que segue foi inspirada em Basso $(2007$; 2011) e nos interessa pelo fato de sistematizar as combinações possíveis de trações acionais, os adjuntos relevantes e a interpretação a que podemos chegar. Temos assim um bom ponto de partida para avaliarmos o que os adjuntos podem fazer, quais interpretações geram e quais combinações são possíveis.
} 


\section{2. 'EM X TEMPO' E 'POR X TEMPO'}

Utilizando algumas das ideias apresentadas acima, mostraremos as distinções entre os adjuntos 'em X tempo' e 'por X tempo' através das tabelas abaixo, nas quais aparecem os traços de telicidade $([ \pm \mathrm{t}])$ e duratividade $([ \pm \mathrm{d}])$, e uma possível interpretação para cada uma das sentenças apresentadas ${ }^{11}$

Tabela 2. Sentenças com o adjunto 'em X tempo'

\begin{tabular}{|c|c|c|c|}
\hline \multicolumn{4}{|l|}{ 'em X tempo' } \\
\hline Imperfectivo & $\mathbf{t}$ & d & Interpretação \\
\hline (12) João estava desenhando uma casa em 10 minutos. & + & + & habitual/genérica \\
\hline (13) João estava perdendo o jogo em 10 minutos. & + & - & habitual/genérica \\
\hline (14) João estava correndo em 10 minutos. & - & + & habitual/genérica \\
\hline (15) João estava ficando bravo em 10 minutos. & - & + & habitual/genérica \\
\hline
\end{tabular}

\begin{tabular}{|l|c|c|c|}
\hline \multicolumn{1}{|c|}{ Perfectivo } & t & d & Interpretação \\
\hline (16) João desenhou uma casa em 10 minutos. & + & + & Télica \\
\hline (17) João perdeu o jogo em 10 minutos. & + & - & Télica \\
\hline (18) João correu em 10 minutos. & - & + & Incoativa \\
\hline (19) João ficou bravo em 10 minutos. & - & + & Incoativa \\
\hline
\end{tabular}

As sentenças que veiculam evento perfectivo combinadas com o adjunto 'em X tempo' adquirirem uma interpretação habitual e/ou genérica independente dos traços de telicidade ou duratividade, ou seja, para todas as classes acionais, a única possível interpretação para essa combinação seria uma leitura segundo a qual, fundamentalmente, não falamos de uma única ocorrência (episódica) do evento denotado/referido pelo predicado verbal. Tomemos a sentença (12), que traz um evento télico (um accomplishment) imperfectivo combinado com o adjunto 'em 10 minutos':

(12) João estava desenhando uma casa em 10 minutos.

${ }^{11}$ A interpretação saliente com relação à sentença em (12) segundo a qual João não tem mais a habilidade de desenhar uma casa em 10 minutos é, provavelmente, o resultado de uma implicatura conversacional generalizada griceana. Não entraremos, contudo, nessa discussão aqui. 
$\mathrm{Na}$ sentença em (12), uma interpretação possível é de que João tem habilidade para fazer algo em 10 minutos, que é, no caso, desenhar uma casa. Idealizando, podemos pensar num contexto em que João utiliza essa atividade como algum ponto de referência (i.e. testar suas habilidades como desenhista), e também que ele conseguia realizar essa atividade em 10 minutos, mas parou de treinar e consequentemente não consegue mais; em tal cenário, encontramos a interpretação sugerida para a sentença $(12)^{12}$. Essa mesma interpretação vale, com alguns ajustes, aos eventos dos outras classes acionais.

Contudo, quando mantemos o adjunto 'em X tempo', e consideramos eventos télicos no aspecto perfectivo, o adjunto 'em X tempo' medirá o tempo transcorrido até o alcance do telos do evento em questão. O exemplo abaixo ilustra essa configuração:

(16) João desenhou uma casa em 10 minutos.

Na sentença em (16), a interpretação télica é esperada, pois é um tipo de sentença no qual um evento com um traço télico positivo é combinado com o aspecto perfectivo e, ceteris paribus, o telos foi alcançado ao fim do tempo medido pelo adjunto 'em 10 minutos'.

Por sua vez, para os eventos atélicos, a única interpretação possível - que é provavelmente o resultado de algum tipo de coerção (cf. AUTOR, 2007; 2008) - é a de uma leitura incoativa, segundo a qual o que o adjunto mede é o tempo anterior ao início do evento. Ou seja, o adjunto combinado com tal predicado marca uma medida de tempo que é referente ao tempo necessário para que o evento veiculado se inicie. Tomemos a sentença abaixo:

(18) João correu em 10 minutos.

O evento veiculado pelo predicado 'correr', na sentença (18), tem um início marcado pelo adjunto temporal 'em 10 minutos' a partir de um momento temporal anterior saliente ou contextualmente dado ${ }^{13}$. Tomemos um cenário como exemplo: podemos considerar que João havia acabado de chegar na academia que frequenta, e que faz um aquecimento de 10 minutos antes de começar a correr; nesse caso, a sentença 'João correu em 10 minutos' é plausível e o início do evento em questão marcado se deu em 10 minutos, contados da chegada de João à academia (o momento contextualmente relevante para este cenário) ${ }^{14}$.

${ }^{12}$ Desconsideramos interpretações que levam em conta alguma medida de distância contextualmente fornecida ou recuperada, que tornaria o evento em questão um evento télico. A interpretação que nos interessa é aquela que surge quando consideramos um evento atélico.

${ }^{13}$ É importante salientar que a interpretação incoativa sugerida para a configuração aqui apresentada pode não ser muito acessível, mas é a única possível. Tal fato pode servir para revelar a função de um adjunto como 'em X tempo'.

${ }^{14}$ É possível uma leitura habitual se considerarmos, por exemplo, que João tinha o costume de fazer algo: "João tinha o costume de nadar durante 10 minutos." Tal interpretação parece existir também para 'por X tempo': "João estava nadando por 10 minutos sempre que ia na academia”. Contudo, parece ser mais saliente para 'durante $\mathrm{X}$ tempo'; algo que ainda precisa ser investigado. 
BASSO \& BERGAMINI-PEREZ - Adjuntos temporais e measure phrases: uma proposta semântica

Vejamos agora o que ocorre quando modificamos a combinação das sentenças, usando desta vez o adjunto temporal 'por X tempo'.

Tabela 3. Sentenças com do adjunto 'por X tempo'

\begin{tabular}{|c|c|c|c|}
\hline \multicolumn{4}{|l|}{ 'por X tempo' } \\
\hline Imperfectivo & $\mathbf{t}$ & d & Interpretação \\
\hline (20) João estava desenhando uma casa por 10 minutos. & + & + & Pt de focalização \\
\hline (21) João estava perdendo o jogo por 10 minutos. & + & - & Pt de focalização \\
\hline (22) João estava correndo por 10 minutos. & - & + & Pt de focalização \\
\hline (23) João estava ficando bravo por 10 minutos. & - & + & Pt de focalização \\
\hline
\end{tabular}

\begin{tabular}{|l|c|c|c|}
\hline \multicolumn{1}{|c|}{ Perfectivo } & t & d & Interpretação \\
\hline (24) João desenhou uma casa por 10 minutos. & + & + & Detelicização \\
\hline (25) João perdeu o jogo por 10 minutos. & + & - & Detelicização \\
\hline (26) João correu por 10 minutos. & - & + & duração do evento \\
\hline (27) João ficou bravo por 10 minutos. & - & + & duração do evento \\
\hline
\end{tabular}

Quando o adjunto 'por X tempo’ é combinado com qualquer classe acional no aspecto imperfectivo, a interpretação mais saliente disponível é a de 'ponto de focalização', que, segundo AUTOR (2011), mede o tempo de evento que transcorreu até esse ponto de focalização, coincidente com a measure phrase (MP) do adjunto. Essa interpretação fica saliente ao se introduzir um outro evento na sentença, como em (20a) e (22a):

(20a) João estava desenhando uma casa por 10 minutos [quando ouviu um barulho].

(22a) João estava correndo por 10 minutos [quando a esposa dele chegou].

O evento "ouvir um barulho", em (20a) é interpretado como acontecendo exclusivamente no (ou logo depois do) ponto de focalização determinado pelo adjunto 'por X tempo', que, no caso, foi após 10 minutos em que João estava desenhando uma casa. O início do evento ‘ouvir um barulho’ é dado pelo adjunto e coincide com a measure phrase do primeiro evento, ou seja, no exemplo utilizado, somente depois de 10 minutos é que são desencadeados quaisquer outros eventos subsequentes denotados por um predicado verbal. As mesmas considerações valem, mutatis mutandis, para (22a): a esposa de João chegou 10 minutos após ele ter iniciado o evento de correr, ou seja, o início do segundo evento coincide com o tempo no qual o primeiro evento é delimitado pela measure phrase do adjunto.

Para o caso de eventos télicos, sua combinação com o adjunto 'por X tempo' faz com que a interpretação dessas sentenças seja de detelicização (cf., AUTOR, 2001). Ou seja, trata-se da situação em que temos um evento télico que ocorreu, cessou, mas seu telos não foi necessariamente atingido. 
(24) João desenhou uma casa por 10 minutos.

Se utilizarmos a sentença (24) como exemplo, temos o predicado que veicula o evento télico de desenhar uma casa veiculado com o aspecto perfectivo e combinado com o adjunto 'por X tempo' ('por 10 minutos'). Considerando ainda as ideias propostas por AUTOR (2011) e AUTOR e Pires de Oliveira (2010), é esperado que ocorra a detelicização do evento em questão. Esta proposta pode ser analisada com uma simples adição de um evento qualquer posterior a esse, tomemos a sentença (24) e adicionemos um evento qualquer posterior, por exemplo:

(24a) João desenhou uma casa por 10 minutos [e foi dormir.]

Neste caso, não é possível determinar com certeza se o telos foi alcançado, pois não podemos dizer se João terminou ou não de desenhar uma casa, ainda que os eventos reportados sejam perfectivos.

Os adjuntos modificam um evento denotado por um predicado e possibilitam diferentes interpretações que dependem das combinações que são feitas, de modo que cada adjunto suscita interpretações específicas. No que segue, analisaremos, nos moldes do que vimos nesta seção, os adjuntos 'durante $\mathrm{X}$ tempo', 'de X a Y tempo' e 'até X tempo', que, como dissemos, não foram alvos de investigações na literatura especializada.

\section{OS DEMAIS ADJUNTOS TEMPORAIS}

Nesta seção, nos dedicaremos à análise semântica dos demais adjuntos temporais que são foco deste artigo, começando por 'durante X tempo'.

\section{1. "durante $\mathrm{X}$ tempo",}

Apresentamos abaixo as combinações de 'durante $\mathrm{X}$ tempo' que investigaremos:

Tabela 4. Sentenças com a combinação do adjunto 'durante X tempo'.

\begin{tabular}{|l|c|c|c|}
\hline \multicolumn{4}{|c|}{ 'durante X tempo' } \\
\hline Imperfectivo & t & d & interpretação \\
\hline (28) João estava arrumando o quarto durante 10 minutos. & + & + & Pt de focalização \\
\hline (29) João estava perdendo o jogo durante 10 minutos. & + & - & Pt de focalização \\
\hline (30) João estava nadando durante 10 minutos. & - & + & Pt de focalização \\
\hline (31) João estava com dor de cabeça durante 10 minutos. & - & + & Pt de focalização \\
\hline
\end{tabular}


BASSO \& BERGAMINI-PEREZ - Adjuntos temporais e measure phrases: uma proposta semântica

\begin{tabular}{|l|c|c|c|}
\hline \multicolumn{1}{|c|}{ Perfectivo } & t & d & interpretação \\
\hline (32) João arrumou o quarto durante 10 minutos. & + & + & detelicização \\
\hline (33) João perdeu o jogo durante 10 minutos. & + & - & detelicização \\
\hline (34) João nadou durante 10 minutos. & - & + & duração do evento \\
\hline (35) João teve dor de cabeça durante 10 minutos. & - & + & duração do evento \\
\hline
\end{tabular}

A tabela acima salienta a grande semelhança entre os adjuntos 'durante $\mathrm{X}$ tempo' e 'por X tempo', considerando todas as classes acionais e os aspectos perfectivo e imperfectivo. Grosso modo, podemos dizer que 'durante X tempo' mede uma duração que vai do início do evento até um ponto de focalização, que é dado pela MP do adjunto.

A interpretação de ponto de focalização ${ }^{15}$ fica bastante saliente quando acrescentamos, às sentenças com eventos imperfectivos da tabela acima, um outro evento, como abaixo ${ }^{16}$.

(28) João estava arrumando o quarto durante 10 minutos [quando sua mãe chegou].

(29) João estava perdendo o jogo durante 10 minutos [quando sua mãe chegou].

(30) João estava nadando durante 10 minutos [quando sua mãe chegou].

(31) João estava com dor de cabeça durante 10 minutos [quando sua mãe chegou].

O evento veiculado por 'quando sua mãe chegou' se localizará no fim da MP do adjunto.

Considerando agora o adjunto 'durante X tempo' combinado com eventos veiculados no aspecto perfectivo, vemos também uma interpretação de detelicização, semelhante ao adjunto 'por X tempo':

(32) João arrumou o quarto durante 10 minutos.

Com (32), não sabemos se o quarto está ou não arrumado.

E quando o adjunto 'durante $\mathrm{X}$ tempo' é combinado com um predicado que veicula um evento atélico, temos uma interpretação de duração de evento, como ocorre com 'por X tempo':

(34) João nadou durante 10 minutos.

(35) João teve dor de cabeça durante 10 minutos.

${ }^{15}$ É importante lembrar que, quando temos um evento não-durativo, que é o caso em (29), consideramos apenas a fase inicial pragmaticamente associada ao evento veiculado.

${ }^{16} \mathrm{E}$ e esse mesmo tipo de diferença entre MPs serão exploradas também para os adjuntos 'de X a Y tempo' e 'até X tempo'. 
Na sentença (35), João teve dor de cabeça durante 10 minutos e não mais que isso, ou seja, o adjunto determina o tempo que durou o evento, assim como seria com a mesma sentença combinada com o adjunto 'por X tempo'.

Apesar de haver muitas similaridades entre os adjuntos 'durante $\mathrm{X}$ tempo' e 'por X tempo', há também importantes (e interessantes) diferenças entre eles, como as possibilidades do que pode ser a measure phrase (MP) de cada um deles ${ }^{17}$.

Nosso primeiro passo será, então, fazer uma importante distinção entre dois tipos de measure phrase, que chamaremos de "primária" e "secundária": measure phrases primárias (MPPs) são cronológicas e/ou dadas por uma medição explícita de tempo, como 'manhã', 'verão'18, '10 minutos', '1 hora', etc; measure phrases secundárias (MPSs) são dadas por elementos não cronológicos que podem ser tomados como referência e/ou parâmetro de duração, como 'jogo', 'filme', 'peça', etc.

Com essa distinção entre MPs em mente, vejamos os exemplos abaixo:

(36) João correu durante a manhã.

(37) João correu pela manhã.

(38) João correu durante 10 minutos.

(39) João correu por 10 minutos.

(40) João correu durante o jogo.

(41) ? João correu pelo jogo.
(42) João correu durante o filme.

(43) ? João correu pelo filme.

(44) João passeou durante o verão.

(45) João passeou pelo verão.

(46) João passeou durante o Natal.

(47) ? João passeou pelo Natal.

Com o par (36)-(37), temos um período na MP dos dois adjuntos indicado por 'manhã', que se refere a um intervalo de tempo anterior ao meio-dia, pragmaticamente “ajustável”, veiculado por uma measure phrase primária. O mesmo padrão se repete nos pares (38)-(39) - ('10 minutos') - e (44)-(45) - ('o verão') -, em que a MP indica uma medida de tempo estabelecida por contagem.

Contudo, vemos que o paralelismo entre 'por $\mathrm{X}$ tempo' e 'durante $\mathrm{X}$ tempo' de fato depende do que compõe a measure phrase, e nem sempre 'por X tempo' é compatível com MPSs; isso fica claro ao vermos o contraste entre os pares (40)-(41), (42)-(43) e (46)-(47), em que as medidas de tempo são dadas, respectivamente, por 'o jogo', 'o filme', e 'o Natal' ${ }^{\prime}$.

17 Algumas medidas primárias são pragmaticamente "ajustáveis”, assim, 'manhã' não necessariamente se refere sempre a um período de tempo que vai das $6 \mathrm{hs}$ às $12 \mathrm{hs}$, 'verão' tem também uma intepretação bem flexível, entre outros exemplos.

${ }^{18}$ Seria possível argumentar que 'Natal' se refere a uma measure phrase primária, mas seus contornos temporais parecem ter muito mais a ver com festividades e preparativos do que com uma medida de tempo mais precisa.

${ }^{19}$ Podemos representar essa intuição mais formalmente como $\mathrm{t} \subseteq \mathrm{t} 1$, em que $\mathrm{t}=$ tempo que João correu e t1 $=$ tempo do jogo. 
Note que, para o caso do par (40)-(41), não estamos falando do jogo em si, mas sim sobre a quantidade de tempo que este leva. Podemos considerar, por exemplo, um jogo de tênis, que não apresenta uma quantidade de tempo exata vinculada a ele. De acordo com a sentença (40), João correu durante um período de tempo no qual o jogo ocorreu, seja este qual for. Além disso, não podemos necessariamente dizer se João correu durante todo o tempo do jogo, ou seja, do início ao fim, ou se ele correu durante uma parcela de tempo no qual o jogo ocorria, não tendo uma limitação obrigatória. Em outras palavras, com (40) temos que a corrida do João levou, pelo menos, um tempo menor ou igual ao do jogo, e que há uma sobreposição desses tempos, de modo que o tempo do jogo, por assim, dita e contém o tempo da corrida do João ${ }^{20}$. Considerações semelhantes podem ser feitas para os exemplos em (42) e (46), em que temos uma measure phrase secundária, com a qual uma medida de tempo externa é considerada.

Por sua vez, a sentença (41) é estranha e possibilita uma interpretação - ainda que pouco saliente - não encontrada para (40), qual seja: se tomarmos 'jogo' como denotando o espaço em que um jogo se dá (por exemplo, uma quadra), podemos interpretar (41) como dizendo que João correu pela quadra. Em tal interpretação, não estamos mais falando de tempo, mas sim de espaço ${ }^{21}$. Tomemos um outro par de exemplos para ilustrar esse fato:

(48) ? João correu durante o campo.

(49) João correu pelo campo.

Nesse caso, é a sentença (49) que é aceitável ao passo que (48) é estranha. A medida dada é externa, e pode ser considera secundária, mas não é temporal, e sim espacial. Outros exemplos deixam claro que 'por X tempo' é compatível com medidas espaciais e temporais primárias, ao passo que 'durante $\mathrm{X}$ tempo' somente é compatível com medidas temporais, tanto primárias quanto secundárias:

(50) ? João passeou durante a cidade.

(51) João passeou pela cidade.

É interessante ainda notarmos que essas peculiaridades se mantêm independentemente do traço de telicidade associado aos eventos, como atestam os seguintes exemplos:

${ }^{20}$ As sentenças (43) e (47) não permitem tal interpretação simplesmente porque as medidas externas consideradas, 'o filme' e 'o Natal' não permitem leituras espaciais que são, de toda forma, pouco acessíveis.

${ }^{21}$ As siglas HAB, GEN e FOC estão, respectivamente, por "habitual”, "genérico" e "ponto de focalização", e remetem rigorosamente aos conceitos que vimos nas seções anteriores. 
Cadernos de ESTUDOS LINGUIISTICOS (58.2) - mai./ago. 2016

Tabela 5. 'durante $\mathrm{X}$ tempo' com eventos atélicos e télicos, perfectivos e imperfectivos

\begin{tabular}{|l|l|}
\hline \multicolumn{1}{|c|}{ Atélico/Perfectivo } & \multicolumn{1}{c|}{ Télico/Perfectivo } \\
\hline $\begin{array}{l}\text { (54a) João correu durante a manhã. } \\
\text { (54b) João correu pela manhã. }\end{array}$ & (59a) João lavou a louça durante a manhã. \\
(55a) João correu durante o jogo. & (59b) João lavou a louça pela manhã. \\
(55b) ? João correu pelo jogo. & $(60 \mathrm{~b})$ ? João lavou a louça pelo jogo. \\
(56a) João correu durante 10 minutos. & (61a) João lavou a louça durante 10 minutos. \\
(56b) João correu por 10 minutos. & (61b) João lavou a louça por 10 minutos. \\
(57a) João correu durante o filme. & (62a) João lavou a louça durante o filme. \\
(58b)? João correu pelo filme. & (62b) ? João lavou a louça pelo filme. \\
(58a) ? João correu durante o campo. & (63a)? João trocou de roupa durante o campo. \\
(58b) João correu pelo campo. & (63b) João trocou de roupa pelo campo. \\
\hline
\end{tabular}

\begin{tabular}{|c|c|}
\hline \multicolumn{1}{|c|}{ Atélico/Imperfectivo } & Télico/Imperfectivo \\
\hline $\begin{array}{c}\text { (64a). João estava correndo durante } \\
10 \text { minutos. }\end{array}$ & $\begin{array}{c}\text { (66a) João estava lavando a louça durante } \\
10 \text { minutos. }\end{array}$ \\
$\begin{array}{l}\text { (64b). João estava correndo por } 10 \\
\text { minutos. }\end{array}$ & $\begin{array}{c}\text { (66) João estava lavando a louça por } 10 \\
\text { minutos. }\end{array}$ \\
$\begin{array}{l}\text { (65a). João estava correndo durante } \\
\text { o filme. }\end{array}$ & $\begin{array}{c}\text { (67a) João estava lavando a louça durante } \\
\text { o filme. }\end{array}$ \\
(65b) ? João estava correndo pelo \\
filme.
\end{tabular}

Como resumo do que vimos, podemos apresentar as seguintes generalizações das relações entre os adjuntos 'durante X tempo' e 'por X tempo' e as diferentes MPs, lembrando que essa generalização se mantém independentemente dos traços de telicidade e do aspecto:

\begin{tabular}{|c|c|c|}
\hline & 'durante X tempo' & 'por X tempo' \\
\hline MP primária & $\mathrm{OK}$ & $\mathrm{OK}$ \\
\hline MP secundária & $\mathrm{OK}$ & $\varnothing$ \\
\hline MP espacial & $\varnothing$ & $\mathrm{OK}$ \\
\hline
\end{tabular}

Quadro 1. Compatibilidades de 'durante X tempo' e 'por X tempo' 
BASSO \& BERGAMINI-PEREZ - Adjuntos temporais e measure phrases: uma proposta semântica

As conclusões a que chegamos mostram que o adjunto 'durante $\mathrm{X}$ tempo' é exclusivamente dedicado a medidas de tempo, combinando-se com MPs primárias ou secundárias, mas não com medidas espaciais, como é o caso, por exemplo, do adjunto 'por X tempo'. Sendo assim, os efeitos que esperamos ver com as leituras temporais de 'por X tempo' (ponto de focalização e detelicização) são exemplificadas de modo ainda mais forte com 'durante $\mathrm{X}$ tempo', e foi isso, de fato, que os exemplos que vimos nos mostraram.

Passemos à análise do adjunto 'de X a Y tempo', e depois 'até X tempo', utilizando as ideias apresentadas.

\section{2. 'de X a Y tempo'}

Abaixo, as combinações envolvendo o adjunto 'de $\mathrm{X}$ a $\mathrm{Y}$ tempo' que investigaremos aqui:

Tabela 6. Sentenças com a combinação do adjunto 'de X a Y tempo'

\begin{tabular}{|c|c|c|c|}
\hline \multicolumn{4}{|l|}{ 'de X a Y tempo' } \\
\hline Imperfectivo & $\mathbf{t}$ & d & interpretação \\
\hline (68) João estava arrumando o quarto de 5 a 10 minutos. & + & + & $\mathrm{HAB} / \mathrm{GEN} ; \mathrm{FOC}$ \\
\hline (69) João estava perdendo o jogo de 5 a 10 minutos. & + & - & $\mathrm{HAB} / \mathrm{GEN} ; \mathrm{FOC}$ \\
\hline (70) João estava nadando de 5 a 10 minutos. & - & + & $\mathrm{HAB} / \mathrm{GEN}$; FOC \\
\hline (71) João estava ficando triste de 5 a 10 minutos. & - & + & HAB/GEN; FOC \\
\hline
\end{tabular}

\begin{tabular}{|l|c|c|c|}
\hline \multicolumn{1}{|c|}{ Perfectivo } & t & d & interpretação \\
\hline (72) João arrumou o quarto de 5 a 10 minutos. & + & + & detelicização \\
\hline (73) João perdeu o jogo de 5 a 10 minutos. & + & - & detelicização \\
\hline (74) João nadou de 5 a 10 minutos. & - & + & duração do evento \\
\hline (75) João ficou triste de 5 a 10 minutos. & - & + & duração do evento \\
\hline
\end{tabular}

Considerando as sentenças de (68) - (71), vemos que, para o caso de sentenças no aspecto imperfectivo combinadas com o adjunto 'de X a Y tempo', temos tanto uma interpretação habitual, não-episódica, quanto uma interpretação de ponto de focalização. Vejamos cada uma delas na sequência.

$\mathrm{Na}$ interpretação habitual, temos algo similar à combinação de um predicado verbal no aspecto imperfectivo com o adjunto 'em X tempo'. Como podemos ver nos exemplos abaixo:

(12) João estava desenhando uma casa em 10 minutos.

(68) João estava arrumando o quarto de 5 a 10 minutos. 
Podemos ver, na comparação entre as sentenças (12) e (68) $)^{22}$, que, em ambos os casos, João tem o costume, hábito ou capacidade de realizar o evento de desenhar uma casa em 10 minutos, e o evento de arrumar o quarto de 5 a 10 minutos. A mesma interpretação é válida para todos os outros predicados apresentados na primeira parte da tabela 6 , que combina o adjunto com eventos imperfectivos. Além disso, há uma diferença importante entre (12) e (68) - ou, melhor dizendo, entre os adjuntos 'em X tempo' e 'de X a Y tempo' - que tem a ver com o alcance do telos dos eventos veiculados: somente 'em X tempo' garante a leitura télica do evento; ‘de X a Y tempo’ não garante que o telos tenha sido alcançado. Portanto, (68) não afirma que o quarto esteja arrumado; essa impossibilidade aproxima 'de $\mathrm{X}$ a Y tempo' a 'por X tempo'.

É interessante notar que, para esse adjunto, a interpretação de ponto de focalização, que o adjunto ‘por X tempo’ apresenta, também está disponível, como atestam os exemplos abaixo - tal interpretação fica mais saliente ao inserirmos o advérbio 'já':

(68a) João (já) estava arrumando o quarto de 5 a 10 minutos (quando ouviu um barulho).

(70a) João (já) estava nadando de 5 a 10 minutos (quando ouviu um barulho).

E, ao mesmo tempo, sem a continuação 'quando ouviu um barulho', mas ainda com o advérbio 'já', a interpretação de repetição, hábito ou capacidade também está disponível:

(68b) João já estava arrumando o quarto de 5 a 10 minutos.

(70b) João já estava nadando de 5 a 10 minutos.

Podemos notar, através da comparação dos adjuntos vistos até aqui no aspecto imperfectivo, que as possíveis interpretações nesse aspecto são bastante homogêneas, independente do adjunto, predicado ou traços dos eventos utilizados. Como hipótese, podemos dizer que isso se deve ao fato de que o imperfectivo, para o momento considerado como relevante, pede que o ponto final (seja ele o telos ou não) de qualquer evento seja desconsiderado, justamente para entretermos o evento em seu desenvolvimento; porém, isso não quer dizer que não haverá a medição de algo, pois os eventos têm duração.

Essa breve análise prevê também que deveríamos esperar que a combinação de adjuntos temporais com eventos não-durativos veiculados no imperfectivo fossem estranhas, justamente porque tais eventos não têm uma duração (pragmaticamente relevante) que possa ser mensurada. Contudo, tal previsão não se realiza, como mostram os exemplos abaixo:

\footnotetext{
${ }^{22}$ Os adjuntos mostrados em (12) e (68) estão relacionados a eventos diferentes, mas ambos são télicos e durativos.
} 
BASSO \& BERGAMINI-PEREZ - Adjuntos temporais e measure phrases: uma proposta semântica (13) João estava perdendo o jogo em 10 minutos. (interpretação habitual/genérica)

(21) João estava perdendo o jogo por 10 minutos. (interpretação de ponto de focalização)

(29) João estava perdendo o jogo durante 10 minutos. (interpretação de ponto de focalização)

(69) João estava perdendo o jogo de 5 a 10 minutos. (interpretação habitual/genérica)

Para o caso das sentenças (21) e (29), como já mostramos acima, podemos salientar a interpretação de ponto de focalização ao inserirmos um outro evento em sequência:

(21a) João estava perdendo o jogo por 10 minutos [quando virou o jogo e passou a ganhar].

Ou seja, após 10 minutos João, que estava perdendo, virou o jogo e começou a ganhar.

Para o caso das sentenças em (13) e (69), como vimos, as interpretações possíveis são as habituais. Em ambos os casos (i.e., os pares (21) e (29), e (13) e (69)), as interpretações sugeridas resultam somente porque estamos levando em consideração a chamada 'fase preparatória' pragmaticamente associada a eventos do tipo achievement, e é a essa fase preparatória que a contribuição dos adjuntos se aplica.

Em resumo, mesmo quando consideramos eventos não-durativos no imperfectivo, temos interpretações possíveis devido ao acesso à fase preparatória pragmaticamente associada a esses eventos, que recebe a mediação das MPs de cada um dos adjuntos investigados.

Vejamos agora o que temos ao considerarmos eventos veiculados no aspecto perfectivo combinados com o adjunto 'de X a Y tempo'. Tomemos as sentenças abaixo, que veiculam eventos télicos:

(72) João arrumou o quarto de 5 a 10 minutos.

(73) João perdeu o jogo de 5 a 10 minutos.

Estamos diante de uma interpretação de detelicização, simplesmente porque estamos considerando eventos télicos perfectivos, mas dos quais não podemos afirmar se alcançaram seu telos, ou seja, se João arrumou o quarto completamente (72), ou se João ao final do jogo havia perdido (73).

Para salientar tal interpretação, vejamos as sentenças abaixo:

(72a) João arrumou o quarto de 5 a 10 minutos e terminou.

(72b) João arrumou o quarto de 5 a 10 minutos e não terminou.

(76) ? João arrumou o quarto em 10 minutos e terminou.

(77) ?? João arrumou o quarto em 10 minutos e não terminou. 
A sentença (72) admite tanto que João alcançou o telos (i.e., (72a)), quanto que João não o tenha alcançado (i.e., (72b)), ao passo que (76) e (77) são ruins, porque são, respectivamente, redundante e contraditória.

A partir disso, podemos dizer que, para o caso da combinação com predicados que veiculam eventos télicos no aspecto perfectivo, o adjunto 'de X a Y tempo' se assemelha ao adjunto 'por X tempo', ou seja, temos uma interpretação de detelicização.

Olhando agora para o caso de sentenças que veiculam eventos atélicos no aspecto perfectivo, detectamos uma interpretação de duração do evento:

(74) João nadou de 5 a 10 minutos.

(75) João ficou triste de 5 a 10 minutos.

Em (74) e (75) temos a medição, dada pela MP do adjunto, da duração do evento.

Contudo, há uma peculiaridade interessante nesse caso, o adjunto 'de X a Y tempo' é o primeiro caso de um adjunto que parece não tomar o início do evento para realizar a medição de sua MP - ou seja, o ' $\mathrm{X}$ ' da MP não precisa ser o começo do evento; antes, ele pode tomar um ponto no desenrolar do evento em questão para ser o início de sua MP, e assim estabelecer uma mediação no desenrolar de tal evento, independentemente de quando ele tenha começado. Quanto a isso, note que paráfrases razoáveis para (74) e (75) seriam algo como:

(78) João passou de 5 a 10 minutos nadando.

(79) João passou de 5 a 10 minutos (ficando/estando) triste.

E não necessariamente sabemos a duração total de tempo que João nadou, apesar de sabermos que ao final da MP (i.e., 5 a 10 minutos) o evento cessou.

Indiretamente, o adjunto insere um ponto específico dentro de um intervalo de tempo, que coincide com o final de sua MP e que acaba deixando o telos do evento não necessariamente incluído, levando à interpretação de detelicização ${ }^{23}$.

$\mathrm{O}$ aspecto perfectivo, de acordo com a base teórica utilizada neste trabalho, considera o início e o final do evento já determinado, e assim, o que indicamos por 'Y' em 'de X a Y tempo' será necessariamente o ponto final do evento (que pode ou não ser o telos).

Podemos agora voltar às sentenças que veiculavam eventos no aspecto imperfectivo e que permitiam leitura habitual e de ponto de focalização:

(68) João estava arrumando o quarto de 5 a 10 minutos.

${ }^{23}$ Os exemplos que vimos acima mostram isso. Em (72a) temos um caso em que o telos está dentro da MP (e por isso podemos usar o predicado 'terminar') e em (72b) temos um caso em que o telos está fora da MP (e por isso não podemos usar o predicado 'terminar'). Lembramos também que a detelicização é simplesmente o telos não ser necessariamente alcançado (e não algo como ser não necessariamente alcançado). 
BASSO \& BERGAMINI-PEREZ - Adjuntos temporais e measure phrases: uma proposta semântica (68a) João já estava arrumando o quarto de 5 a 10 minutos (quando ouviu um barulho).

Note que em (68), quando temos leitura de hábito ou repetição, o adjunto equivale, grosso modo, a 'em X tempo', isso quer dizer que o final da MP do adjunto 'de X a Y tempo', o "Y”, se identifica com o telos do evento, e temos uma medida de quanto tempo, aproximadamente, João levava para arrumar o quarto. Por sua vez, em (68a), quando temos leitura de ponto de focalização, o adjunto 'de $\mathrm{X}$ a Y tempo' se assemelha ao adjunto 'por X tempo', e o final de sua MP, o "Y", não se identifica com o telos do evento.

Em relação às possíveis MPs que o adjunto 'de $\mathrm{X}$ a $\mathrm{Y}$ tempo' admite, a tabela 6, acima, deixa claro que ele se combina com MPs primárias. Para o caso de MPs secundárias, o adjunto 'de X a Y tempo' as admite sob algumas condições, que, em geral, têm a ver com considerar dois pontos diferentes dentro da MP secundária, de modo a um deles ser o início (i.e., 'de X') e um deles ser o fim (i.e., 'a Y') da medição:

(80) João estava correndo do início do jogo ao fim.

(81) João arrumou o quarto da novela ao filme.

(82) João ficou triste do supermercado a sua casa.

Essas observações ainda precisam ser muito mais aprofundadas e mais testes podem ser desenvolvidos para podermos identificar as restrições atuantes aqui, mas é interessante notar a dinâmica do adjunto 'de X a Y tempo' e seu funcionamento, algo que, até onde sabemos ainda não foi explorado para o PB no âmbito da semântica de eventos. trabalho.

Passemos agora ao adjunto 'até X tempo', o último que investigaremos neste

\section{3. 'até X tempo'}

Como no caso de 'durante X tempo' e 'de X a Y tempo', o adjunto 'até X tempo' apresenta certas similaridades com o adjunto 'por X tempo', e também algumas especificidades. Para começar nossa análise, tomemos as sentenças da tabela abaixo:

Tabela 7. Sentenças com a combinação do adjunto

\begin{tabular}{|l|c|c|c|}
\hline \multicolumn{4}{|c|}{ 'até X tempo' } \\
\hline \multicolumn{1}{|c|}{ Imperfectivo } & t & d & interpretação \\
\hline (83) João estava arrumando o quarto até anoitecer. & + & + & Pt de Focalização \\
\hline (84) João estava perdendo o jogo até anoitecer. & + & - & Pt de Focalização \\
\hline (85) João estava nadando até anoitecer. & - & + & Pt de Focalização \\
\hline (86) João estava ficando triste até anoitecer. & - & + & Pt de Focalização \\
\hline
\end{tabular}


Cadernos de ESTUDOS LINGUIISTICOS (58.2) - mai./ago. 2016

\begin{tabular}{|l|c|c|c|}
\hline \multicolumn{1}{|c|}{ Perfectivo } & t & d & interpretação \\
\hline (87) João arrumou o quarto até anoitecer. & + & + & Detelicização \\
\hline (88) João perdeu o jogo até anoitecer. & + & - & Detelicização \\
\hline (89) João nadou até anoitecer. & - & + & Duração de evento \\
\hline (90) João ficou triste até anoitecer & - & + & Duração de evento \\
\hline
\end{tabular}

Se considerarmos as interpretações das sentenças (83)-(86), podemos afirmar que o adjunto 'até $\mathrm{X}$ tempo' é similar ao adjunto 'por X tempo': ambos, quando combinados com eventos imperfectivos, independente de seus traços acionais, apresentam uma interpretação de ponto de focalização para todos os casos (e não uma interpretação de hábito, ou capacidade ${ }^{24}$ ), e uma interpretação de duração de evento e detelicização quando consideramos eventos perfectivos.

No entanto, há uma importante diferença entre esses adjuntos, que tem a ver com as MPs que eles podem receber: 'até $X$ tempo' não se combina com MPs primárias ((83a) e (85a)) nem com MPs secundárias ((83b) e (85b)):

(83a) ? João estava arrumando o quarto até 10 minutos.

(85a) ? João estava nadando até 10 minutos.

(83b) ? João estava arrumando o quarto até o filme ${ }^{25}$.

(85b) ? João estava nadando até o filme.

A MP que se combina com o adjunto 'até $\mathrm{X}$ tempo' deve conter um outro evento, considerado, por sua vez, como o limite temporal do adjunto. Na verdade, podemos dizer que 'até $\mathrm{X}$ tempo' pode tomar outros eventos e transformá-los em limites temporais, que servirão, para o caso de combinação com eventos veiculados no aspecto imperfectivo, como ponto de focalização.

Devido ao fato de as MPs que se combinam com 'até $\mathrm{X}$ tempo' se referirem a outros eventos, e não a medidas de tempo, vamos chamá-las de MP atemporais (MPAs). Nesse sentido, podemos dizer que 'até X tempo' não toma nem MPPs, nem MPSs, mas, transforma em limites temporais outros eventos (i.e., anoitecer, a bomba explodir, romper o ligamento do joelho, etc.).

\footnotetext{
${ }^{24}$ Como notou um parecerista anônimo, é possível, para essas sentenças, produzir uma leitura de hábito se inserirmos medidas temporais explícitas, como: "João estava arrumando o quarto até as 10 da manhã; agora, por preguiça, deixa para arrumar depois do almoço". Esses casos, contudo, não invalidam nossa argumentação. Agradecemos às observações do parecerista.

${ }^{25}$ Por ora, desconsiderar casos em que temos algo como 'João estava arrumando o quarto até o filme começar/até o começo do filme'. Mais adiante, veremos como nossa proposta captura esse tipo de sentença.
} 
Como conclusão sobre esse adjunto, podemos dizer que 'até X tempo' é muito parecido com 'por X tempo', sendo a maior diferença entre eles o que pode ser tomado como a MP de 'até X tempo'. É importante, antes de passarmos às conclusões de nossa pesquisa, fazermos uma breve consideração sobre uma ambiguidade suscitada pelo item 'até'.

\subsubsection{Sobre a ambiguidade de 'até'}

O item 'até' pode aparecer no domínio tempo-aspectual em configurações como as abaixo - note que, como exemplo, consideraremos apenas um evento télico (um accomplishment, 'desenhar uma casa') e um evento atélico (uma atividade, 'correr'):

(91) João estava desenhando uma casa em até 10 minutos.

(92) João estava correndo em até 10 minutos.

(93) João desenhou uma casa em até 10 minutos.

(94) João correu em até 10 minutos.

(95) João estava desenhando uma casa por até 10 minutos.

(96) João estava correndo por até 10 minutos.

(97) João desenhou uma casa por até 10 minutos.

(98) João correu por até 10 minutos.

(99) João estava desenhando uma casa durante até 10 minutos.

(100) João estava correndo durante até 10 minutos.

(101) João desenhou uma casa durante até 10 minutos.

(102) João correu durante até 10 minutos.

(103) João estava desenhando uma casa de 5 a até 10 minutos.

(104) João estava correndo de 5 a até 10 minutos.

(105) João desenhou uma casa de 5 a até 10 minutos.

(106) João correu de 5 a até 10 minutos.

Como podemos ver, o item 'até' pode aparecer combinado com qualquer um dos outros adjuntos que vimos (menos com 'até X tempo', que não toma medidas temporais). Contudo, nessas combinações, vemos que 'até' tem um comportamento muito semelhante a construções quantificacionais como 'no máximo', como as paráfrases abaixo sugerem (selecionamos somente um exemplo de cada adjunto): 
(107) João estava desenhando uma casa em no máximo 10 minutos.

(108) João estava correndo por no máximo 10 minutos.

(109) João desenhou uma casa durante no máximo 10 minutos.

(110) João correu de 5 a no máximo 10 minutos.

É importante não confundirmos os usos de 'até, e, em nossa pesquisa, nosso foco, como deve ter ficado transparente, foi o adjunto 'até X tempo'26.

Na próxima seção, apresentaremos um balanço das ideias e nossas principais conclusões.

\section{BALANÇO DAS IDEIAS}

O principal objetivo deste artigo foi investigar certos adjuntos temporais - 'durante X tempo', 'de X a Y tempo' e 'até X tempo' - para entender seu funcionamento no domínio tempo-aspectual, buscando as interpretações que ensejam e as restrições que obedecem, para podermos ter uma melhor descrição do funcionamento dessas construções em PB e das restrições e interpretações que possibilitam. Nossa análise tomou como base os já bastante estudados adjuntos 'em X tempo' e 'por X tempo'.

As interpretações que cada um dos adjuntos investigados apresenta podem ser identificadas na tabela abaixo:

Tabela 8. Adjuntos, aspectos e interpretações

\begin{tabular}{|c|c|c|c|c|c|c|c|}
\hline \multirow{2}{*}{ Aspecto } & \multicolumn{2}{|c|}{$\begin{array}{c}\text { Traços } \\
\text { acionais }\end{array}$} & \multicolumn{5}{c|}{ Adjuntos } \\
\hline & T & d & $\begin{array}{c}\text { em X } \\
\text { tempo }\end{array}$ & $\begin{array}{c}\text { por X } \\
\text { tempo }\end{array}$ & $\begin{array}{c}\text { durante } \\
\text { X tempo }\end{array}$ & $\begin{array}{c}\text { de X a Y } \\
\text { tempo }\end{array}$ & $\begin{array}{c}\text { até X } \\
\text { tempo }\end{array}$ \\
\hline \multirow{2}{*}{$\begin{array}{c}\text { I } \\
\text { M } \\
\text { P }\end{array}$} & + & + & HAB & PF & PF & HAB/PF & PF \\
\cline { 2 - 8 } $\begin{array}{c}\text { E } \\
\text { R }\end{array}$ & - & - & HAB & PF & PF & HAB/PF & PF \\
\cline { 2 - 8 } F. & - & + & HAB & PF & PF & HAB/PF & PF \\
\hline
\end{tabular}

${ }^{26}$ A nosso ver, uma análise interessante para o item 'até' mostrará que ele não é ambíguo e também que não temos dois itens diferentes na língua, mas sim um item com interpretação escalar, que sempre se relaciona com pontos maximais ou terminais de escalas. Contudo, não temos como perseguir essa importante e instigante questão aqui. 
BASSO \& BERGAMINI-PEREZ - Adjuntos temporais e measure phrases: uma proposta semântica

\begin{tabular}{|l|c|c|c|c|c|c|c|}
\hline \multirow{2}{*}{$\mathrm{P}$} & + & + & TEL & DET & DET & DET & DET \\
\cline { 2 - 8 } $\mathrm{E}$ & + & - & TEL & DET & DET & DET & DET \\
\cline { 2 - 8 } $\mathrm{R}$ & - & + & INC & DUR & DUR & DUR & DUR \\
\cline { 2 - 8 } F. & - & + & INC & DUR & DUR & DUR & DUR \\
\hline
\end{tabular}

Os adjuntos investigados são todos muito mais próximos de 'por X tempo' do que de 'em $X$ tempo'. O único adjunto que foge um pouco ao padrão seria 'de $\mathrm{X}$ a Y tempo', e as causas para ele ter as duas possibilidades de interpretação, segundo o que argumentamos, têm a ver com a maneira de interpretarmos sua measure phrase (MP).

$E$ é justamente com relação às MPs que cada um desses adjuntos aceita que encontramos as maiores diferenças entre eles. Vimos três tipos de MPs: primárias, secundárias e atemporais (como 'anoitecer', 'ouvir um barulho', etc.). Considerando essas MPs, a tabela abaixo sintetiza os resultados que alcançamos:

Tabela 9. Adjuntos e suas MPs

\begin{tabular}{|l|c|c|c|c|c|}
\hline \multicolumn{1}{|c|}{ MPs } & \multicolumn{5}{|c|}{ Adjuntos } \\
\hline & em X tempo & por X tempo & durante X tempo & $\begin{array}{c}\text { de X a Y } \\
\text { tempo }\end{array}$ & $\begin{array}{c}\text { até X } \\
\text { tempo }\end{array}$ \\
\hline Primária & OK & OK & OK & OK & $\varnothing$ \\
\hline Secundária & $\varnothing$ & $\varnothing$ & OK & $(\text { ok })^{27}$ & $\varnothing$ \\
\hline Atemporal & $\varnothing$ & $\varnothing$ & $\varnothing$ & $\varnothing$ & OK \\
\hline
\end{tabular}

Os resultados, obviamente, ainda são preliminares, e mais investigações precisam ser feitas, mas acreditamos estar diante de um interessante panorama de alguns dos principais adjuntos temporais do PB.

Notamos que temos, em primeiro lugar, o adjunto 'em X tempo', de um lado, e todos os outros adjuntos, de outro lado. A diferença entre 'por X tempo', 'durante X tempo' e 'até X tempo' tem a ver com as MPs que cada um deles aceita. $\mathrm{E}$ a diferença entre esses e 'de X a Y tempo' tem a ver com de que modo os limites da MP de tal adjunto é interpretada - considerando o início ou fim dos eventos, ou considerando o seu desenrolar. Como vimos, essas possibilidades geram as diferentes intepretações que 'de X a Y tempo' pode ter.

Em nosso trabalho, fico clara a necessidade de distinguirmos tipos de diferentes de MPs, reconhecermos que os adjuntos temporais modificam, mais do classificam, a interpretações dos predicados verbais com os quais se combinam. Futuramente, uma outra análise pode propor uma formalização, dentro da semântica de eventos, dos fenômenos que descrevemos e das distinções que propomos.

\footnotetext{
${ }^{27}$ Ver, na seção 3.2, as restrições que 'de X a Y tempo' impõe a MPs secundárias.
} 


\section{BIBLIOGRAFIA}

AUTOR.

AUTOR

AUTOR.

AUTOR, e PIRES DE OLVEIRA, R. 2010.

BERTINETTO, Pier Marco. (1982). "Intrinsic and extrinsic temporal reference. On restricting the notion of 'reference time"'. Journal of Italian Linguistics, p. 71-108.

BERTINETTO, Pier Marco. (1986). Tempo, Aspetto e Azione nel verbo italiano. Il sistema dell'indicativo. Florença: Accademia della Crusca.

BERTINETTO, P. M. On a frequent misunderstanding in the temporal-aspectual domain: The 'Perfective $=>$ Telic Confusion'.In: Carlo Cecchetto, Gennaro Chierchia \& Maria Teresa Guasti (eds.), Semantic Interfaces [Reference, Anaphora and Aspect], CSLI Publications, Stanford, Cal.: 177-210 [vers. prec. in: Quaderni del Laboratorio di Linguistica della SNS 1, n.s./2000].

CHIERCHIA, Gennaro. (2003). Semântica. Campinas: Editora Unicamp.

DAVIDSON, Donald. (1967). The Logical Form of Action Sentences. In The Logic of Decision and Action, pp. 81-95. Pittsburgh: University of Pittsburgh Press.

DOWTY, David. (1979). Word Meaning and Montague Gramar. Dordrecht: Kluwer Academic Publishers.

KRIFKA, Manfred. (1998). The origins of telicity. In Rothstein 1998, pp. 197-235.

PARSONS, Terence. (1990). Events in the semantics of English: A study in subatomic semantics. Cambridge: MIT Press.

REICHENBACH, Hans. (1947). Elements of Symbolic Logic. Londres: MacMillan.

ROTHSTEIN, Susan. (1998). Events and Grammar. Dordrecht: Kluwer Academic Publishers.

ROTHSTEIN, Susan. (2004). Structuring Events: A Study in the Semantics of Lexical Aspect. Malden:Blackwell Publishing Ltd.

VENDLER, Zeno. (1957). "Verbs and Times". Philosophical Review, pp. 143-160. In: CECCHETTO, Carlo; CHIERCHIA, Gennaro \& GUASTI, Maria Tereza. (eds.). 